\title{
Livre Empresa e Responsabilidade Social ${ }^{*}$
}

\author{
Alejandro Antonio Chafuen ${ }^{* *}$
}

\begin{abstract}
Resumo: A Responsabilidade Social da Empresa (RSE) pode ser consistente dentro da visão da ética tradicional e da economia liberal? Neste ensaio, o autor responde de maneira afirmativa. Devido ao mero fato de se associarem, as pessoas não se desconectam de sua responsabilidade moral para com o próximo. Lamentavelmente, considera-se como responsabilidade social empresarial o trabalho das empresas em áreas que apresentam pouco controle: salvar animais em extinção, mudanças climáticas e assim por diante. A RSE deve começar em casa. Neste trabalho, o autor propõe princípios para medir adequadamente a elaboração de um índice de RSE.

Palavras-Chave: Responsabilidade Social Empresarial, Ética e Economia, Responsabilidade Social, Livre Mercado.
\end{abstract}

\section{Free Enterprise and Corporate Social Responsibility}

\begin{abstract}
Can Corporate Social Responsibility (CSR) be consistent with the vision of traditional ethics and liberal economics? In this essay, the author answers affirmatively. Due to the mere fact of association, persons do not disconnect of their moral responsibility towards others. Regrettably, what is considered as CSR are the efforts of corporations in areas where they have little control: to save endangered animals, climate changes and so on. CSR should begin at home. In this work, the author proposes principles to properly measure the elaboration of a CSR index.

Keywords: Corporate Social Responsibility, Ethics and Economics, Social Responsibility, Free Market.
\end{abstract}

Classificação JEL: Y8, M14

\footnotetext{
* Uma versão anterior do texto foi publicada como: CHAUFEN, Alejandro A. Libre Empresa y Responsabilidad Social. Caracas: CEDICE, 2006. O presente artigo é o texto revisto e atualizado que foi apresentado pelo autor no dia 15 de abril de 2015 na Fundação Armando Álvares Penteado (FAAP), em evento organizado pelo Instituto Mises Brasil (IMB)

Traduzido do original em espanhol para o português por Claudio A. Tellez-Zepeda.

** Alejando Antonio Chafuen é presidente da Atlas Economic Research Foundation. Cursou a graduação em Economia na Pontificia Universidad Católica Argentina (UCA), em Buenos Aires, na Argentina, e o PhD em Economia no Grove City College, na Pennsylvania, nos EUA. É pesquisador do Acton Institute for the Study of Religion and Liberty, associado da Mont Pelerin Society e da Philadelphia Society, membro associado da John Templeton Foundation, membro do Conselho Acadêmico do Centro Interdisciplinar de Ética e Economia Personalista (CIEEP) e membro do Conselho Editorial de MISES: Revista Interdisciplinar de Filosofia, Direito e Economia. Foi agraciado com o doutorado honoris causa em Economia da Universidad Francisco Marroquín na Guatemala, com o Nassau Institute Freedom Prize, com o Global Leadership Award do Leadership Institute e com o Walter Judd Freedom Award do Fund for American Studies. Escreve uma coluna semanal na revista Forbes norte-americana. É autor de inúmeros artigos científicos publicados em diferentes revistas acadêmicas e do livro Faith and Liberty: The Economic Thought of the Late Scholastics (Lexington Books, 2003), traduzido, atualmente, para o espanhol, italiano, polonês e tcheco.

E-mail: Alex.Chafuen@AtlasNetwork.org
} 


\section{INTRODUÇÃO}

A responsabilidade social empresarial (RSE) é um termo e um campo de estudos cada vez mais popular. Uma análise baseada na ética tradicional e na religião pode dar substância a um conceito que está sendo objeto de abuso por parte dos ativistas políticos.

\section{Temas de Discussão}

No presente estudo, tentarei melhorar a definição e desmistificar parte da análise corrente a respeito da responsabilidade social empresarial. Além disso, fornecerei exemplos de RSE e de comportamento antissocial empresarial (CAE). Em uma tentativa de resumir minhas recomendações, agrupei-as em sete princípios de RSE. Também assinalarei que, com o propósito de avançar, precisamos redefinir alguns dos parâmetros atuais e os indicadores da RSE.

\section{I - Sobre o QUE SE SUSTENTA A RSE?}

\section{I.1 - A Empresa}

A empresa, tal como a conhecemos no mundo desenvolvido, vem evoluindo através dos séculos, chegando a transformar-se em uma organização que revolucionou a produção mais do que qualquer outro esforço da interação humana. Como trata-se de um tema de dimensões globais, devemos estar conscientes de que o conceito de empresa, nos Estados Unidos e em outros países desenvolvidos, é muito diferente da noção que se emprega no resto do mundo.

A ideia de empresa como entidade corporativa gera dúvidas em pessoas com inclinações ideológicas muito diferentes. Um conhecido teólogo da "libertação" norte-americano, Matthew Fox, por exemplo, considera que a atribuição de "personalidade jurídica" a uma empresa é um grande erro. Outros especialistas na matéria sustentam que a "responsabilidade limitada" sobre a qual subjaz a estrutura empresarial é uma das principais causas da irresponsabilidade social empresarial.

Este aspecto da responsabilidade limitada leva a argumentos tais como "nós lhes outorgamos este privilégio, portanto agora vocês têm esta responsabilidade adicional para com a sociedade". Ainda que isto fosse verdade, o fato é que a confusão existente a respeito, conforme demonstrarei nesta análise, questiona as assim chamadas recomendações de RSE. Muitas destas recomendações, ou demandas por ação "social", pelo menos desde o ponto de vista da ética judaico-cristã, promovem um comportamento antissocial.

Dos grandes moralistas do século XX que estudaram a empresa, Oswald Von Nell-Breuning, SJ (1890-1991) foi um dos mais influentes. Na sua análise das empresas anônimas, adverte acerca dos riscos de se cortar o vínculo entre propriedade e gerência, e de enfraquecer o sentido de responsabilidade. Contudo, Nell-Breuning reconhece que abolir as sociedades anônimas de responsabilidade limitada levaria "muito provavelmente a uma imoralidade e corrupção ainda maiores"1.

Irving Kristol, um dos principais expoentes do movimento "neoconservador" nos Estados Unidos, argumentou que "o problema com as grandes corporações de hoje em dia é que não possuem uma clara legitimidade teórica - ou seja, ideológica"2. Seus pontos de vista não são exclusivos, e baseiam-se na influente obra The Modern Corporation and Private Property [A Corporação Moderna e a Propriedade Privada] de Adolf A. Berle, Jr. (18951971) e Gardiner C. Means (1896-1988), publicada originalmente em $1932^{3}$. Outra linha de críticas é aquela baseada em Willard F. Mueller, que sustenta que as sociedades anônimas

\footnotetext{
${ }^{1}$ NELL-BREUNING, Oswald von. Reorganization of Social Economy: The Social Encyclical Developed and Explained. Milwaukee: Herder, 1937. p. 323.
}

${ }^{2}$ BARRY, Normal. Business Ethics. London: Macmillan, 1998. p. xii-xiii.

${ }^{3}$ BERLE, Jr. Adolf A. \& MEANS, Gardiner C. The Modern Corporation and Private Property. London: Macmillan, 1932. 
existem graças às licenças dos governos e que, portanto, estes podem modificar ou revogar as regulações.

Uma defesa muito consistente da empresa, a partir de uma perspectiva da propriedade privada, é aquela elaborada por Robert Hessen. De acordo com suas próprias palavras:

A essência do capitalismo é a inviolabilidade dos direitos individuais, inclusive o direito que alguém tem para utilizar ou investir a própria riqueza da maneira como decidir, e o direito de associar-se com outro para qualquer propósito pacífico e de acordo com os termos de associação que sejam aceitáveis para todas as partes envolvidas ${ }^{4}$.

Hessen não vê nada de errado com a responsabilidade limitada, já que, em sua opinião, aqueles que se associam a ela consideram-na como "um contrato implícito entre os proprietários da corporação e seus credores" 5 ; contudo, assinala uma dificuldade com relação à responsabilidade por culpas extracontratuais. Seguindo o clássico argumento de respondeat superior, Hessen concorda em que a pessoa que contrata e supervisiona alguém que trabalhe para ela deve pagar pelos danos causados a uma terceira parte no exercício de seu trabalho. Hessen alega corretamente que "as empresas não devem ser absolvidas de nenhuma das responsabilidades que são válidas para os indivíduos ou outras organizações, quer sejam empresariais, quer não".

A conclusão de Hessen está completamente de acordo com a ética tradicional:

O princípio adequado de responsabilidade seria que aquele que controla uma empresa, qualquer que seja sua forma legal, deveria ser pessoalmente responsável pelas culpas extracontratuais de seus representantes e empregados. Deste modo, nas associações, a responsabilidade indireta recairia exclusivamente sobre os sócios gerais, enquanto nas

4 HESSEN, Robert. In Defense of the Corporation. Stanford: Hoover Institution Press, 1979. p. xiii.

${ }^{5}$ Idem. Ibidem., p. 18. empresas, os funcionários (sejam proprietários-investidores ou gerentes contratados) seriam os responsáveis. As salvaguardas ao alcance dos sócios gerais e dos funcionários empresariais incluiriam uma seleção mais cuidadosa e maior supervisão do pessoal, assim como a contratação de mais apólices de seguro por responsabilidade ${ }^{6}$.

Hessen sustenta que, ao acomodar-se à lei, "a chamada empresa de um homem só ou a empresa fechada" permite e tolera uma injustiça ${ }^{7}$, por defender aqueles que deveriam ser responsáveis pelos seus erros. Ainda que concorde com Hessen, o ataque à RSE politicamente correta (RSEPC) não costuma concentrar-se sobre estes casos, mas sobre empresas legítimas, em sua maior parte multinacionais e com grandes reservas econômicas. Tentam fazer com que as empresas utilizem seu poder econômico para fins sociais "politicamente corretos".

\section{I.1.a - "Sou responsável pelo meu irmão?"}

O padre Jaime Balmés (1810-1848) observou corretamente que a responsabilidade do homem para com seu semelhante antecede a existência do Estado, e na verdade antecede inclusive os laços familiares. Basta que duas pessoas venham a se conhecer, mesmo que de forma casual e por apenas uns poucos minutos, para que surjam novos deveres.

Antes de examinar os direitos e deveres que se fundamentam na ordem social, é conveniente advertir que, independentemente de qualquer reunião em sociedade, e até dos vínculos familiares, o homem tem obrigações com relação a seus semelhantes. Basta que dois indivíduos se encontrem, ainda que por acaso e por breves momentos, para que nasçam direitos e deveres em conformidade com as circunstâncias ${ }^{8}$.

\footnotetext{
${ }^{6}$ Idem. Ibidem., p. 20.

${ }^{7}$ Idem. Ibidem., p. 20.

8 BALMÉS, Jaime. Curso de Filosofía Elemental. Barcelona: Balmesiana, 1944 [1846-1850]. p. 144.
} 
Balmés utiliza um exemplo que pode ser exposto como estudo de caso no âmbito empresarial. Um grupo de marinheiros, proprietários em conjunto de um navio, depara-se com um ou com vários náufragos; seu dever de ajudá-los é um dever humano. Talvez sua empresa tenha a política de prestar socorro às pessoas que se encontram nessa situação; contudo, ainda que não a tivesse, cada um dos marinheiros teria o direito de utilizar os recursos que pertencem à empresa - por exemplo, os salva-vidas - para cumprir com seu dever humano.

Hessen escreve que "os direitos de qualquer organização ou associação são os direitos que derivam dos indivíduos que a criam e a sustentam"1, e o mesmo pode ser dito a respeito de seus deveres e responsabilidades.

As pessoas temem, com razão, que as empresas, por si sós ou associadas entre si, possam exercer poder político e manipular o governo com o propósito de obter favores e privilégios especiais à custa tanto de outras empresas, quanto dos consumidores.

E conclui:

Não há justificativa para permitir que uma pessoa ou uma organização empresarial inclusive as empresas de qualquer tamanho - alcancem seus objetivos exercendo o poder político ${ }^{10}$.

Norman Barry (1944-2008) tenta contornar as críticas contra o argumento economicista ao escrever:

Todas estas limitações aparentemente virtuosas sobre a gratificação imediata são sanções que se devem a uma preocupação com o valor econômico. Talvez não seja o valor revelado por meio do preço das ações na bolsa, sobre o qual possivelmente há influência de fatores no curto prazo; mas trata-se de uma preocupação com a rentabilidade final o que determina o comportamento empresarial $^{11}$.

\footnotetext{
${ }^{9}$ HESSEN, Robert. In Defense of the Corporation. p. 41.

${ }^{10}$ Idem. Ibidem., p. 111.

${ }^{11}$ BARRY. Business Ethics. p. 74.
}

$\mathrm{Na}$ maior parte do mundo menos desenvolvido, a "pessoa" da empresa é uma entidade totalmente diferente da existente nos Estados Unidos. Nos países em vias de desenvolvimento e em muitos países da Europa, as empresas são frequentemente controladas por apenas um dos membros da família. Raramente respeitam os direitos de propriedade minoritária, inclusive quando se trata de membros familiares. Ainda não me deparei com estudos sérios sobre a RSE que levem em consideração esta diferença tão radical.

\section{I.2 - O Social}

Nas palavras do filósofo e teólogo Dietrich von Hildebrand (1889-1977):

Pressupõe-se que outra pessoa é o destinatário destas ações [sociais]. Não haveria nenhum sentido em fazer uma promessa a um cão, dar uma ordem a uma árvore ou dizer alguma coisa a uma obra de $\operatorname{arte}^{12}$.

Se a noção de empresa ou corporação requer esclarecimentos, precisamos mais ainda esclarecer o significado de "social". Enquanto uns abusam do termo e o definem de acordo com sua visão do que é benéfico para a comunidade, outros - individualistas extremados - negam a dimensão social da pessoa humana. Este não é o caso de grandes entusiastas da sociedade livre, tais como Ludwig von Mises (1881-1973), que utilizava o termo "cooperação social" para descrever a essência da economia de mercado. Henry Hazlitt (1894-1993), que preferia o termo "mutualismo", apoiava esta opinião de Mises, pois "dado que a cooperação social é o grande meio para atingir quase todos os nossos fins, estes meios podem ser considerados, em si mesmos, como o fim moral a ser atingido"13.

12 HILDEBRAND, Dietrich von. Ethics. Chicago: Franciscan Herald Press, 1972 [1953]. p. 206.

13 HAZLITT, Henry. The Foundations of Morality. Irvington-on-Hudson: The Foundation for Economic Education, 1998 [1967]. p. 356. 
F. A. Hayek (1899-1992) escreveu um ensaio muito relevante sobre o abuso do termo "social". Aprovava dois conceitos distintos de "social": um é o que descreve alguma coisa que é "peculiar à sociedade", ou "que surge de um processo social específico". Nesse sentido, escreveu que "temos uma necessidade urgente dessa palavra"14. O outro é quando o "social" se utiliza no sentido de "servir aos interesses da sociedade", porém Hayek concluía que essa utilização "certamente aborda um problema, embora não ofereça uma solução"15.

Como o termo tem sido tão abusado, Hayek evitou utilizá-lo. Ao abordar o tema deste estudo, ele perguntaria: "qual é a diferença entre a responsabilidade corporativa e a responsabilidade social corporativa?". Se as pessoas tivessem, hoje em dia, uma noção clara do aspecto social da pessoa humana, estariam $100 \%$ de acordo com ele, e com grande entusiasmo eu me uniria à sua cruzada para evitar a utilização da palavra. Mas, como não é o caso, opto por continuar utilizando-a, e por trabalhar dentro do "mercado da linguagem", utilizando o termo nos significados aceitos por Hayek.

\section{I.2.a - O Fundamento Ético: Existe a "Ética Social"?}

Para aqueles que acreditam em um só Criador, sua essência ou natureza é a fonte definitiva de moralidade. A norma aproximada é a natureza do ser humano, criado à imagem de Deus. Este não é o espaço adequado para uma análise completa dos fundamentos da ética a partir de uma perspectiva judaico-cristã. É suficiente dizer que minha abordagem do tema desta análise será baseada na ética tradicional ou, pelo menos, em uma visão do ser humano consistente com ela.

A ética social faz distinção dos laços recíprocos entre as pessoas com relação ao fim a

${ }^{14}$ HAYEK, F. A. Studies in Philosophy, Politics, and Economics. Chicago: The University of Chicago Press, 1967. p. 242.

${ }^{15}$ Idem. Ibidem., p. 243. ser alcançado em comum (o bem comum). $\mathrm{O}$ moralista social questiona se uma determinada instituição está cumprindo com sua função natural na sociedade civil. Também investiga o modo como, com o objetivo de buscar o bem comum, distribui os direitos e os deveres entre os membros dessa instituição ${ }^{16}$.

Em ética, estamos preocupados unicamente com as ações livres ou voluntárias: pode-se optar por não realizá-las. Estas ações podem ser diretamente voluntárias ou indiretamente voluntárias, tal como ocorre quando "escolhe-se livremente um objeto do qual se pode prever que outro resultado será produzido"17. Quando fundos são canalizados para as contas de um ditador malvado e seus cúmplices, por exemplo, apoia-se diretamente algo que é mau. Quando se investem ou destinam-se recursos para uma atividade que resultará na criação de empregos e serviços aos seres humanos que vivem em um estado ditatorial, pode-se estar fornecendo, indiretamente, apoio a um ditador.

Os seres humanos são responsáveis por suas ações morais. Tal responsabilidade exige "conhecimento daquilo que estamos fazendo e liberdade de escolha". Alguém será mais ou menos responsável das ações humanas dependendo do grau de conhecimento e de liberdade que possua com relação a essa ação. A concupiscência, o medo e a violência também influenciam na imputabilidade da ação. Esta responsabilidade não desaparece quando uma pessoa passa a fazer parte de uma empresa.

A dignidade da pessoa deveria ser o princípio orientador de qualquer análise sobre RSE. O Catecismo da Igreja Católica (CIC) resume isso de forma muito acertada:

O respeito pela pessoa humana implica o respeito pelos direitos que dimanam da sua dignidade de criatura. Esses direitos são anteriores à sociedade e impõem-se-

16 UTZ, Arthur Fridolin. Ética Social. Barcelona: Editorial Herder, 1964 [1958]. p. 361-62.

17 NOONAN, John P. General and Special Ethics. Chicago: Loyola University Press, 1947. p. 7. 
-lhe. Estão na base da legitimidade moral de qualquer autoridade: desprezando-os ou recusando reconhecê-los na sua legislação positiva, uma sociedade atenta contra a sua própria legitimidade moral. Faltando esse respeito, uma sociedade não tem outra solução, senão o recurso à força e à violência, para obter a obediência dos seus súditos $(\text { CIC } \S 1930)^{18}$.

\begin{abstract}
Além disso,
$\mathrm{O}$ respeito pela pessoa humana passa pelo respeito pelo princípio: "Que cada um considere o seu próximo, sem qualquer excepção, como 'outro ele mesmo', e zele, antes de mais, pela sua existência e pelos meios que lhe são necessários para viver dignamente'. Nenhuma legislação será capaz, por si mesma, de fazer desaparecer os temores, os preconceitos, as atitudes de orgulho e egoísmo que são obstáculo ao estabelecimento de sociedades verdadeiramente fraternas (CIC §1931).
\end{abstract}

Ainda que todas as pessoas humanas tenham igualmente dignidade, seus "talentos" não estão distribuídos de forma equitativa. Estas "diferenças estimulam e muitas vezes obrigam as pessoas à magnanimidade, à benevolência e à partilha: e incitam as culturas a enriquecerem-se umas às outras" (CIC §1937).

Além das desigualdades naturais, existem também desigualdades escandalosas que afetam milhões de homens e mulheres.

A igual dignidade pessoal postula que se chegue a condições de vida mais humanas e justas. Com efeito, as excessivas desigualdades econômicas e sociais entre os membros ou povos da única família humana provocam escândalo e são obstáculo à justiça social, à equidade, à dignidade da pessoa humana e, finalmente, à paz social e internacional (CIC §1938).

${ }^{18}$ Cathecism of the Catholic Church. Washington, D.C.: United States Catholic Conference / Libreria Editrice Vaticana: 1994. [Todas as citações da obra foram substituídas pela passagem equivalente em português da seguinte edição: Catecismo da Igreja Católica. (Edição Típica Vaticana). São Paulo: Loyola, 2000. (N. do T.)].
Os individualistas mais sérios tendem a reconhecer que há uma diferença entre os dilemais morais confrontados por um indivíduo e aqueles enfrentados por uma empresa. Norman Barry admite que "os funcionários empresariais provavelmente devem lidar com dilemas éticos que não concernem ao cidadão comum". Esta afirmação é particularmente acertada no caso dos problemas relacionados ao meio-ambiente, nos quais uma decisão de não poluir, mesmo quando fazê-lo está dentro da legalidade e quando os direitos de propriedade não são decisivos, pode implicar em custos que poderiam ser evitados ${ }^{19}$. $\mathrm{O}$ autor também assinala que:

Surgem graves problemas éticos para as empresas quando os produtores exploram seu conhecimento superior, em detrimento dos consumidores - ou seja, quando as condições do mercado não proporcionam incentivos para o comportamento moral ${ }^{20}$.

Outro tema que gera confusão é a análise da RSE a partir da perspectiva da justiça social. A verdadeira justiça social é uma justiça que transcende a justiça nos tribunais: são os esforços da sociedade civil para ajudar a construir uma ordem social justa. O falso conceito de justiça social, que é "tirar dos 'ricos' para dar aos pobres", é o que prevalece muito mais nos dias de hoje. O ex-ditador Juan Domingo Perón (1895-1974) chegou inclusive a fundar um partido político (Partido Justicialista) baseando-se em uma concepção falsa da justiça social. Hoje, quase sessenta anos depois, o "justicialismo" ainda consegue continuar destruindo a riqueza na Argentina.

A RSE deveria ser considerada como os esforços das empresas em prol de uma verdadeira justiça social. Cumprir com seus contratos e obrigações é matéria de ética de negócios e justiça comutativa, porém não necessariamente de responsabilidade social. Como o termo "justiça social" é ainda mais

\footnotetext{
${ }^{19}$ BARRY. Business Ethics. p. 88.

${ }^{20}$ Idem. Ibidem., p. 88.
} 
equívoco do que o de "responsabilidade social", tento evitar utilizá-lo, inclusive em seu sentido correto.

Dado que a pessoa humana é um ser social, a solidariedade é essencial para preservar a sociedade livre. É necessária para reduzir a desigualdade perante a lei, assim como as desigualdades injustas que resultam dos privilégios governamentais que benefician uns poucos em detrimento de muitos, os quais logo a seguir são contentados com políticas populistas.

\section{I.3 - Responsabilidade}

A noção de responsabilidade é essencial para a sociedade livre. Algumas campanhas de RSE acabam por enfraquecer a responsabilidade pessoal. A responsabilidade pressupõe a existência da liberdade. Dietrich von Hildebrand afirmou que "o primeiro traço importante que distingue os valores morais de todos os demais valores pessoais é o fato de que o ser humano faz-se responsável por eles" ${ }^{\prime 21}$. $\mathrm{O}$ Catecismo da Igreja Católica assinala que:

A liberdade torna o homem responsável pelos seus atos, na medida em que são voluntários. O progresso na virtude, o conhecimento do bem e a ascese aumentam o domínio da vontade sobre os próprios atos (CIC §1734).

Acrescenta, além disso, que:

A imputabilidade e responsabilidade dum ato podem ser diminuídas, e até anuladas, pela ignorância, a inadvertência, a violência, o medo, os hábitos, as afeições desordenadas e outros fatores psíquicos ou sociais (CIC §1735).

Por acaso estas afirmações também são válidas para as empresas?

Deveria haver uma diferença entre a responsabilidade pessoal e a responsabilidade empresarial? A empresa, por estar formada por pessoas diferentes, não possui uma consciência. Poderíamos falar da "cultura" ou do "caráter distintivo" de uma empresa.

${ }^{21}$ HILDEBRAND. Ethics. p. 171.
Entretanto, os responsáveis por uma empresa deveriam esforçar-se para prestar atenção aos pontos de vista de seus membros. Cabe afirmar que, na medida em que uma empresa seja propriedade de apenas um membro da família, mais a RSE será parecida com a RSP (Responsabilidade Social Pessoal). Os deveres sociais do patrão são idênticos aos deveres sociais de sua empresa.

Pompeo Piva sustenta que há uma forte relação entre a responsabilidade individual e a responsabilidade "social":

A responsabilidade individual, por sua própria natureza, tende a produzir uma comunidade de responsabilidade: em certo sentido, é uma viagem do eu para o nós, não ao nós da comunidade orgânica da era pré-moderna, mas sim ao nós da comunidade solidária pós-moderna, na qual assumimos livremente nossa responsabilidade. A norma moral é o fruto da comunidade de responsabilidade ${ }^{22}$.

\section{I.4 - Solidariedade}

O princípio de solidariedade deveria orientar as pessoas e as corporações. Articulada também em termos de "amizade" ou "caridade social", a solidariedade é uma exigência direta da fraternidade humana e cristã.

A solidariedade manifesta-se, em primeiro lugar, na repartição dos bens e na remuneração do trabalho. Implica também o esforço por uma ordem social mais justa, em que as tensões possam ser melhor resolvidas e os conflitos encontrem mais facilmente uma saída negociada (CIC §1940).

Os problemas socioeconômicos só podem ser resolvidos com a ajuda de todas as formas de solidariedade: solidariedade dos pobres entre si, dos ricos com os pobres, dos trabalhadores entre si, dos empresários e empregados na empresa; solidariedade entre as nações e entre os povos. A solidariedade internacional é uma exigência de ordem moral. Dela depende, em parte, a paz do mundo (CIC §1941).

\footnotetext{
${ }^{22}$ PIVA, Pompeo. Sogno di un Imprenditore Cristiano.
} Milano-Genova: Marietti, 2004. p. 79. 
A RSE aborda todos estes temas mencionados nos pontos 1940 e 1941 do Catecismo. Contudo, é necessário ter em mente que, tal como colocado por Karol Wojtyla (1920-2005), que em breve seria o papa João Paulo II, solidariedade nem sempre significa apoiar a política dos governos. A "oposição" é totalmente consistente com a solidariedade. Citando Wojtyla

A oposição não é inconsistente com a solidariedade. Quem deixa transparecer que se opõe às normativas gerais ou particulares da comunidade não rejeita, dessa maneira, seu pertencimento a ela; não retira sua disposição de agir ou de trabalhar em prol do bem comum. [...] Seria demasiado fácil citar intermináveis exemplos de pessoas que contestam - adotando assim a atitude de oposição - devido à sua profunda preocupação com o bem comum (por exemplo, os pais podem estar em desacordo com o sistema educacional ou com seus métodos, devido a que seus pontos de vista com respeito à educação de seus filhos diferem dos pontos de vista das autoridades educacionais ${ }^{23}$.

Seguindo o argumento de Wojtyla, as pessoas, agindo por conta própria ou como representantes de uma empresa, poderiam agir de maneira socialmente responsável ao opor-se à educação pública ou a outros tipos de regulações econômicas. Teríamos dificuldades para encontrar um ativista da RSE que, hoje em dia, colocasse como exemplo positivo a oposição dos donos de empresas às escolas dirigidas pelo governo.

\section{I.5 - Quando o Antissocial Passa-se por RSE nos Meios de Comunicação da Atualidade}

Há numerosos exemplos de RSE que encontram a oposição daqueles que têm pontos de vista tradicionais em questões de ética e religião. Entre estes, inclui-se oferecer benefícios médicos e de outra índole às pessoas que

\footnotetext{
${ }^{23}$ WOJTYLA, Karol. The Acting Person. Trad. Andrzej Potocki. Dordrecht: D. Reidel Publishing Company, 1979 [1969]. p. 286.
}

vivem em situações consideradas contrárias à família tradicional, e apoiar causas ambientalistas radicais, tais como a proibição de experimentações médicas com animais.

Certos esforços no campo da RSE podem ser bem acolhidos por pessoas com pontos de vista socioeconômicos e religiosos muito diferentes. Um bom exemplo é a exposição e luta entre os atos de corrupção cometidos pelas empresas e seus representantes. A busca de privilégios (alguns economistas utilizam o termo infeliz "busca de rendimentos" - rent seeking) também é uma ação criticada por diferentes observadores. Mas nem todas elas o são; o protecionismo às vezes apresenta-se como uma atividade socialmente responsável, e o outsourcing (a contratação de serviços de trabalhadores estrangeiros), que a meu modo de ver é uma via maravilhosa na direção da cooperação e compreensão social, considera-se como antissocial.

Dado que a liberdade econômica é o principal freio contra a corrupção, as empresas que, através de suas atividades, ou mediante doações, apoiam a expansão da liberdade econômica, também deveriam ser consideradas como empresas socialmente responsáveis. Enquanto a RSE não se transforme em um mandato expresso por meio de incontáveis normativas, a maior parte do interesse pela corrupção é saudável. Se os esforços de responsabilidade social levam a lutar contra a corrupção por meio de um emaranhado de regulações e proibições, mais incentivos para o crime serão criados, ao invés de menos.

Em outros trabalhos, mostrei a alta correlação que existe entre a falta do livre mercado, do livre comércio e a corrupção ${ }^{24}$. À medida que a liberdade econômica aumenta, a corrupção tende a diminuir. Isso não é um processo automático, e os habitantes de um

24 CHAFUEN, Alejandro \& GUZMÁN, Eugenio. Economic Freedom and Corruption. In: O'DRISCOLL, Gerald ; HOLMES, Kim \& KIRKPATRICK, Melanie (Eds.). 2000 Index of Economic Freedom. Washington, DC: The Heritage Foundation / Wall Street Journal, 2000. Versão em espanhol: <http://www.atlas.org.ar/ economia/chafuen_guzman.asp $>$. 
país que passa por mudanças radicais precisam de tempo para adaptar-se. Além disso, os mesmos marcos normativos complexos que evoluíram em diversas nações desenvolvidas talvez não mostrem um grande aumento na percepção da corrupção nesses países (ou seja, nos países nórdicos, nos da Europa Ocidental e inclusive nos Estados Unidos e no Canadá). Contudo, esses países têm uma longa tradição de serviço público e igualdade perante a lei, e seus governos também conquistaram uma reputação melhor que a dos países menos desenvolvidos.

A menos que possamos "importar" instituições legais e governamentais, assim como está sendo feito por algumas das nações que ingressam na União Europeia, é provável que a corrupção aumente nos países menos desenvolvidos que tentam copiar os complexos esquemas normativos ocidentais.

\section{II - EM DireçÃo a uma DeFiniçÃo DE RSE}

Se prestarmos atenção aos significados de empresa e de social, e ao conceito de responsabilidade, a RSE define-se como o conceito segundo o qual uma entidade empresarial é responsável pelo impacto de suas ações sobre as pessoas por elas afetadas. Outras definições assinalam que:

RSE é um conceito por meio do qual as empresas, de maneira voluntária, incorporam questões sociais e de meio-ambiente às suas operações e à interação com seus acionis$\operatorname{tas}^{25}$.

Outro autor define a RSE como:

A harmonização das operações empresariais com os valores sociais. A RSE consiste em incorporar os interesses dos acionistas

${ }^{25}$ Comunicación de la Comisión de las Comunidades Europeas relativa a la Responsabilidad Social de las Empresas: Una Contribución Empresarial al Desarrollo Sostenible. 2002. Disponível em: <http://www.aeca.es/comisiones/rsc/documentos_ fundamentales_rsc/ue/comunicacion.pdf $>$.
- todos aqueles que se veem afetados pelo comportamento da empresa - às políticas e às ações da empresa. A RSE concentra-se no êxito social, ambiental e financeiro de uma empresa - os chamados rendimentos líquidos triplos - com o objetivo de influenciar positivamente a sociedade, ao mesmo tempo em que os objetivos econômicos são alcançados ${ }^{26}$.

Todas estas definições não diferem muito de algumas definições de ética empresarial. Como aquela oferecida por Pompeo Piva (1933-2009): “Uma ética que se concentra nos problemas da vida global da empresa moderna" ${ }^{27}$.

Milton Friedman (1912-2006) foi um dos primeiros e mais consistentes opositores da RSE. O Prêmio Nobel de economia alega que:

Poucas tendências poderiam minar de forma tão absoluta as próprias bases de nossa sociedade livre como a de que os executivos empresariais, em vez de ganharem tanto dinheiro quanto possível para seus acionistas, aceitassem a chamada responsabilidade social. Trata-se de uma doutrina fundamentalmente subversiva ${ }^{28}$.

Em uma economia livre, para Friedman: A empresa possui apenas uma responsabilidade social - utilizar seus recursos e levar a cabo atividades desenhadas para incrementar seus ganhos desde que as regras do jogo sejam respeitadas; o que significa praticar a concorrência livre e aberta, sem enganar e nem cometer fraude ${ }^{29}$.

E conclui que "é responsabilidade do resto de nós estabelecer um marco legal" ${ }^{\prime 30}$.

26 CONNOLLY, Meghan L. Corporate Constraints on Social Responsibility. Brattleboro: School for International Training, 2001.

${ }^{27}$ PIVA. Sogno di un Imprenditore Cristiano. p. 75.

28 FRIEDMAN, Milton. Capitalism and Freedom. Chicago: University of Chicago Press, 1962. p. 133.

${ }^{29}$ Idem. Ibidem., p. 133.

${ }^{30}$ Idem. Ibidem., p. 133. 
Existe isso que é chamado de "ética empresarial"? Há muito tempo, Santo Agostinho (354-430) escreveu algo que foi aceito pela maior parte dos moralistas e que pode ser parafraseado da seguinte maneira: "É o empresário, e não a empresa, quem age de modo pouco ético" [Vitia sunt negotiantis non negoti]. Podemos fazer a mesma colocação quando se trata da responsabilidade empresarial. A responsabilidade recai sobre o empresário, e não sobre a empresa. Contudo, ainda que a responsabilidade moral corresponda ao ator, na medida em que o ator responsável dirige muito mais recursos do que possui, sua responsabilidade transcende os recursos que lhe pertencem.

O fato de que a empresa pública com responsabilidade limitada prevaleça como uma estrutura jurídica importante para o setor produtivo nas economias desenvolvidas, tais como a dos Estados Unidos, originou a noção de Responsabilidade Social Empresarial e também a agenda de seus promotores. Em inglês, o termo para referir-se à RSE é Corporate Social Responsibility (ou business social responsibility, onde business refere-se a "empresa" ou "corporação"). A ideia de corporação sempre traz à mente a noção de grupo. Contudo, em muitas partes do mundo, independentemente da figura jurídica, as empresas pertencem a ou são controladas por uma só pessoa. Raramente os interesses dos acionistas minoritários são respeitados, inclusive se são membros da família. É difícil encontrar estudos de RSE que levem em consideração a diferença radical entre as empresas de propriedade difusa e aquelas onde a propriedade está concentrada.

Como poucas pessoas têm a possibilidade de transformar-se em acionistas dessas empresas, as atividades dos que desejam exercer influência sobre elas para que atuem de uma certa maneira em matéria de metas e instituições sociais são muito diferentes das que se realizam nos Estados Unidos. Estas pessoas exercem pressão não como acionistas, mas sim como supostos stakeholders, "pessoas com interesses" e, especialmente, como clientes. Naqueles países que possuem um Estado de Direito fraco, os ativistas da RSE poderiam tentar utilizar funcionários corruptos em benefício de sua causa. Os empresários, entretanto, poderiam oferecer mais do que eles na hora de comprar esses burocratas.

O distanciamento entre a direção de uma empresa e alguns de seus donos em outras partes do mundo é descrito de maneira correta e com abundante pesquisa empírica em Corporate Governance in Development: The experiences of Brazil, Chile, India, and South Africa $(C I P E-O C D E)^{31}$. A situação é particularmente problemática na América do Sul, onde:

A concentração da posse e o exercício quase absolutista do poder por parte das famílias e dos acionistas controladores é uma característica fundamental das estruturas brasileiras de condução empresarial ${ }^{32}$.

Apesar destas diferenças, alguns dos melhores livros sobre RSE vêm destes países. Um deles é o de Charo Méndez Rivas, que coloca ênfase nos esforços das grandes empresas familiares em prol de seus empregados e da sociedade em geral: ações que vão muito além das suas obrigações contratuais ${ }^{33}$. A RSE, nesses casos, não é mais do que a ação responsável dos proprietários e sua decisão livre de beneficiar setores da sociedade que transcendem as necessidades básicas da empresa.

A RSE é mais forte em países com mercados de capitais desenvolvidos. As pessoas com ideologias diferentes tentam comprar ações suficientes das empresas com o propósito de influenciar seu comportamento de

31 OMAN, Charles P. (Ed.). Corporate Governance in Development: The Experiences of Brazil, Chile, India, and South Africa (CIPE-OECD). 2003. Disponível em: <http://www.oecd-ilibrary. org/development/corporate-governance-indevelopment_9789264106598-en>.

${ }^{32}$ Idem. Ibidem., p. 66.

${ }^{33}$ MÉNDEZ RIVAS, Charo. Responsabilidad Social de Empresarios y Empresas en Venezuela durante el Siglo XX. Caracas: Strategos Consultores, 2003. 
acordo com suas noções de RSE. Contudo, para captar recursos para a sua causa, precisam ter uma política baseada em uma lista de ações consideradas socialmente responsáveis. A ordem dos Irmãos Cristãos (Christian Brothers), por exemplo, está colocando em prática aquilo que prega a respeito da transparência, quando fazem uma lista do que é correto e do que é incorreto na política de investimentos que utilizam para administrar sua carteira de 4 bilhões de dólares. A maior parte dessa política está totalmente de acordo com a ética judaico-cristã tradicional. Uma das exigências é a de não intervir em empresas que elaborem produtos para o controle da natalidade. Outras políticas, como a de não investir em empresas que fabricam cigarros, e ao mesmo tempo estarem abertos para investir em empresas que produzem material pornográfico, desde que este não represente mais de $50 \%$ de suas vendas, parecem, de certo modo, estranhas. Mesmo hoje em dia, na Doutrina Social da Igreja Católica e em seu Catecismo, a produção e o consumo de cigarros e de bebidas alcoólicas não são especialmente condenados; condena-se somente seu abuso e consumo excessivo. Os cristãos tradicionais realmente condenam a pornografia de maneira mais enérgica, mas este não é o caso na política de investimentos desta ordem religiosa dos Irmãos Cristãos.

Em minha análise é evidente que, distintamente de Friedman, não vejo nada de errado no conceito de RSE em si mesmo. Vejo muitas coisas erradas nas noções atuais de empresa, responsabilidade e o "social". Compartilho da preocupação do padre Robert Sirico:

Ainda mais surpreendente do que o viés anticapitalista entre o clero é o viés que existe entre os próprios capitalistas. Em tentativas equivocadas para alcançar um alto grau de 'responsabilidade social' para suas empresas, alguns líderes empresariais sucumbiram a falsos pontos de vista do mercado. Ao mesmo tempo em que geram riqueza para a sociedade através de empresas exitosas, apoiam causas contrárias ao crescimento econômico, a livre empresa e a liberdade humana. Por que a retórica da "responsabilidade social empresarial" parece ter um viés tão anticapitalista? ${ }^{34}$

\section{II.1 - A Necessidade de Desenvolver Indicadores}

Alguns aspectos conflitantes da RSE nunca serão resolvidos, dado que sempre haverá grandes diferenças entre as opiniões das pessoas com relação aos temas religiosos, sociais e jurídicos. Entretanto, existem diversos argumentos anedóticos no debate em torno da RSE. Com o propósito de contar com sólidos princípios éticos e religiosos de RSE, torna-se necessário elaborar alguns indicadores adequados.

No Japão, a Integrex, uma firma independente de pesquisas com sede em Tóquio, elabora classificações de RSE com base na integridade empresarial, cumprimento de preceitos éticos e transparência. A Integrex envia questionários para aproximadamente 3.600 empresas japonesas, das quais 877 qualificaram para a avaliação de RSE. Outra empresa, chamada $\mathrm{MHCi}$, elabora um índice diferente, que leva em conta 50 indicadores distintos.

Como acontece com qualquer índice novo, o tempo, uma análise melhor e o refinamento de alguns aspectos ajudará a separar os bons dos ruins. A alta volatilidade dos cálculos ou a falta de correlações significativas deveriam levar-nos a procurar maneiras de refiná-los. São o resultado de uma lógica fraca, da escassez de dados ou de um Estado de Direito debilitado?

Os escândalos recentes na Enron em 2001 e da Shell em 2004, empresas que promoveram o conceito de RSE e que mostraram bons resultados aos olhos de alguns ativistas, mostram que ainda temos muito o que aprender quando se trata de calcular a RSE.

Como uma orientação para analisar os índices de RSE, elaborei o seguinte modelo em formato de tabela. Também poderia ser

${ }^{34}$ SIRICO, Robert. The Entrepreneurial Vocation. Grand Rapids: Acton Institute, 2001. p. 15. 
desenvolvido como uma função do tipo RSE $=F(n, x, y, z)$, onde RSE é uma função da natureza da empresa $(n)$; as ações e o impacto de suas relações com os participantes internos ( $x$, primeiro grau de responsabilidade); participantes externos ( $y$, segundo grau de responsabilidade); e os participantes mais distantes ( $z$, terceiro grau de responsabilidade). ambientalistas radicais, orientados por uma definição estreita de desenvolvimento sustentável, considerariam como irremediáveis as empresas petroleiras baseadas na exploração e extração de combustíveis fósseis (uma atividade não sustentável). Até mesmo desde o ponto de vista da ética cristã tradicional, o tópico da natureza da atividade é um tema di-

\begin{tabular}{|l|l|l|l|}
\hline \multicolumn{1}{|c|}{$\mathbf{N}$} & \multicolumn{1}{|c|}{$\begin{array}{c}\text { Primeiro grau } \\
\text { de responsabilidade (x) }\end{array}$} & $\begin{array}{c}\text { Segundo grau } \\
\text { de responsabilidade (y) }\end{array}$ & \multicolumn{1}{|c|}{$\begin{array}{c}\text { Terceiro grau } \\
\text { de responsabilidade (z) }\end{array}$} \\
\hline $\begin{array}{l}\text { Natureza da empresa: } \\
\text { (algumas empresas } \\
\text { fabricam produtos } \\
\text { considerados } \\
\text { antisociais) }\end{array}$ & $\begin{array}{l}\text { Participantes internos: } \\
\text { a. acionistas } \\
\text { b. pessoal }\end{array}$ & $\begin{array}{l}\text { Participantes externos: } \\
\text { a. clientes } \\
\text { b. fornecedores } \\
\text { c. credores } \\
\text { d. autoridades governamentais } \\
\text { e. vizinhos }\end{array}$ & \\
\hline & & & $\begin{array}{l}\text { Participantes mais distantes: } \\
\text { a. início da cadeia de } \\
\text { suprimentos } \\
\text { b. impacto do produto nas } \\
\text { "águas subterrâneas" } \\
\text { c. "Planeta" }\end{array}$ \\
\hline & & & \\
\hline
\end{tabular}

A seguir, temos alguns exemplos que poderiam servir para explicar este modelo.

A natureza da empresa ( $n$ ): consideremos o caso de uma empresa que tem como principal atividade a produção de bens e serviços considerados antissociais. É bastante conhecido que os narcotraficantes são muito generosos com as comunidades nas quais habitam; mas não importa o quanto eles sejam "socialmente responsáveis" com suas fortunas, poucas pessoas os colocariam em uma boa posição em um índice de medição da responsabilidade social. Ainda que não seja necessário chegar a tais extremos, aqueles que avaliam a RSE mas estão convencidos de que matar bebês no útero é algo ruim, nunca dariam uma boa classificação em matéria de RSE à Planned Parenthood ou a qualquer outro praticante ou promotor de abortos. Por outra parte, os fícil de abordar. Há uma passagem nas escrituras, aquela do administrador infiel, na qual parte da mensagem é "fazei-vos amigos com a riqueza injusta" (Lc 16,9). O caso dos Irmãos Cristãos, mencionado anteriormente, cujas políticas contra os vendedores de cigarros são mais estritas do que suas medidas referentes aos distribuidores de pornografia, é um bom exemplo do quanto é difícil elaborar diretrizes de RSE que sejam aceitáveis para todos os cristãos.

\section{II.1.a - Primeiro Grau de Responsabilidade (x)}

Observo que, para ser socialmente responsável de verdade, uma empresa precisa primeiramente comportar-se responsavelmente em seu foro mais íntimo: com seus proprietários ou seus acionistas, e com seus tra- 
balhadores. Uma empresa cumpre uma função social somente se produz mais valor do que consome. A principal responsabilidade para com os donos e o pessoal é a de respeitar todos os contratos justos. Na filosofia moral tradicional, este tema cairia no âmbito da justiça comutativa. Há uma área, contudo, que pertence à justiça distributiva: as normas que determinam o quanto cada participante recebe pelos bens mantidos em propriedade conjunta. Determinar dividendos, colocar membros da família em posições-chave e outorgar prêmios e recompensas aos executivos não é uma ciência exata, e muitos proprietários têm sido vítimas de injustiças por parte dos executivos. Podem-se fornecer diversos exemplos, tanto de empresas privadas, quanto públicas. A alta gerência da Shell (Royal Dutch Shell), para mencionar um exemplo, empresa que vem promovendo a RSE e que muitos consideram como campeã neste campo devido a suas doações "socialmente responsáveis", falsificou os dados de suas reservas petrolíferas conhecidas. A magnitude de sua falsificação ( $20 \%$ de todas as suas reservas) supera amplamente a soma de todos os donativos que realizou ao longo de sua existência. Além dos aspectos legais, este tipo de fraude contábil é socialmente irresponsável.

\section{II.1.b - Segundo Grau de Responsabilidade (y)}

Uma vez que a empresa cumpre com suas obrigações em seu foro íntimo, deve atender à sua responsabilidade com os participantes externos: clientes, fornecedores, credores, autoridades governamentais e vizinhos. Em diferentes graus, todos esses participantes são cruciais para a rentabilidade da empresa. Assim como acontece $\operatorname{com} x$, a primeira regra consiste em cumprir com todas as leis e contratos justos. Contudo, à medida que aumenta a quantidade de pessoas afetadas pela empresa, torna-se mais necessário levar em consideração outros fatores. Não buscar privilégios governamentais, por exemplo, pode ser visto, em algumas circunstâncias, como uma ação que vai na direção contrária à dos lucros, dos proprietários e dos trabalhadores. Contudo, para a sociedade como um todo, buscar tais privilégios pode implicar no detrimento de todos. Clientes, fornecedores, credores, autoridades governamentais e vizinhos também interagem com muitas outras empresas, e o comportamento egocêntrico de uma empresa pode afetar de maneira negativa os participantes externos.

\section{II.1.c - Terceiro Grau de Responsabilidade (z)}

Este último grau de responsabilidade é, curiosamente, o que domina a discussão sobre a RSE. De que modo as atividades de uma empresa poderiam afetar "o planeta" recebe, em muitos casos, mais atenção do que fraudar o próprio pessoal ou os acionistas. Pede-se às empresas que compram açúcar de intermediários ou cooperativas que verifiquem se mão de obra infantil não foi utilizada para plantar ou colher o produto. Da mesma maneira, os inquisidores da RSE lançam-se ao ataque contra ampresas se alguém utiliza o produto de alguma empresa de um modo não previsto pelo vendedor, pela natureza do uso ou pelo seu abuso. Cheirar cola para drogar-se ou o consumo excessivo de álcool, cigarros ou hambúrgueres são bons exemplos. O fato de se considerar estes participantes "mais distantes" como terceiros na linha de responsabilidade não quer dizer que esteja negando sua importância. Devido à natureza de seu processo de produção, uma empresa envolvida com energia nuclear, por exemplo, deve preocupar-se com o impacto de suas operações sobre o planeta. Se as pessoas estão utilizando um produto que eu fabrico de uma maneira antissocial, é um assunto de decência humana; e, dentro de certos limites, que eu tente fazer algo para mitigar o problema, ainda que isto afete meus lucros. E se, nas primeiras etapas de minha cadeia de suprimentos, encontro violações dos direitos humanos ou condutas criminosas, deveria preocupar-me com isso e avaliar o impacto na sociedade, e não somente sobre os lucros. As sociedades anônimas também deveriam preocupar-se. 
Vale a pena sublinhar que todos os participantes mencionados aqui $(x, y, z)$, e não somente os participantes internos $(x)$, ajudam, através da sociedade civil, a estabelecer as regras do jogo do mercado que possibilitam os lucros, assim como a função social da empresa.

\section{Conclusão}

Nesta altura do século XXI, quando os governos são, em média, cinco vezes maiores do que há um século, parece impossível evitar que os governos e suas agências tentem ser atores nos temas de moda e politicamente corretos. Na atualidade, poucos temas são tão populares quanto a RSE no âmbito das ONGs. O papel das agências governamentais - tanto nacionais quanto internacionais - deve orientar-se para promover uma disposição na qual a RSE seja recompensada. Também poderiam desempenhar um papel na difusão dos bons exemplos. Não poderão, entretanto, evitar o conflito produzido pelos pontos de vista diferentes e encontrados a respeito do que é social na RSE.

Há esperanças de alcançarmos uma compreensão melhor da RSE? Creio que o surgimento de indicadores contribuirá para dar mais seriedade à discussão. Não obstante, a principal área de crescimento potencial está nos países não desenvolvidos e dependerá do surgimento de um Estado de Direito baseado em um governo limitado e no respeito à propriedade privada. As empresas podem desempenhar um papel positivo ou obstrucionista neste sentido. Seus líderes são responsáveis por estas decisões. Provavelmente, seu comportamento empresarial dependerá da natureza de sua vantagem comparativa. Se dependem de um privilégio, provavelmente agirão como obstrucionistas; se são justos com seus concorrentes, desempenharão um papel positivo. Muitas das decisões empresariais estarão em uma zona cinzenta, talvez convivendo, porém não dando alento à corrupção e aos privilégios.
A Theory of Corruption [Uma Teoria da Corrupção] ${ }^{35}$, de Samuel Gregg e Osvaldo Schenone, é um dos primeiros livros que combinam a análise teológica com a teoria econômica da corrupção. Este livro, complementado com os estudos empíricos a respeito da liberdade $^{36}$, pode servir como base para aqueles que se concentram na corrupção com um dos grandes temas da RSE.

Ficará nas mãos daqueles que trabalham no campo dos estudos sociais e econômicos, e daqueles que apontam para uma alta meta moral, baseando suas recomendações na verdade, serem eficientes em sua maneira de pressionar para que o comportamento empresarial seja verdadeiramente social e respeitoso da dignidade humana.

Com visões tão divergentes acerca do que é a responsabilidade social empresarial e do que é, na realidade, um comportamento antissocial, não somente entre os empresários, mas inclusive dentro de ordens religiosas, parece ser muito difícil chegar a consensos. Sem clareza moral e uma sólida compreensão da realidade empresarial e econômica, a RSE irá transformar-se simplesmente em uma palavra altissonante, porém vazia. Como antídoto e resumo, enumerarei sete princípios de RSE, como guia para aqueles que são responsáveis pelas ações de uma empresa:

1) Negue-se a busca de privilégios.

2) Mantenha uma contabilidade impecável.

3) Seja cuidadoso ao escolher seus sócios.

4) Seja meticuloso na observância das leis justas.

5) Promova a proteção e o respeito das leis justas.

6) Comece sendo responsável com seus trabalhadores, clientes e consigo mesmo.

7) Preste atenção a todos os proprietários, e não somente aos mais ruidosos e prepotentes.

${ }^{35}$ GREGG, Samuel \& SCHENONE, Osvaldo. A Theory of Corruption. Grand Rapids: Acton Institute, 2004.

${ }^{36}$ CHAFUÉN \& GUZMÁN. Economic Freedom and Corruption. 
Muitos destes princípios dependem de como entendemos os termos, especialmente o de lei "justa", que, por motivos de espaço, não abordaremos aqui ${ }^{37}$. Mas, para os que estão familiarizados com a Doutrina Social Católica, o significado é claro: as leis injustas não são leis.

Sam Gregg, um dos analistas mais lúcidos a respeito destes temas, escreveu o que considero como uma conclusão muito boa: a aparição da teoria dos stakeholders mostra que os conselhos administrativos, assim como os executivos, devem estar conscientes da direção e caráter das discussões sobre políticas públicas. Isto exigirá um compromisso mais ativo para com o mundo das ideias, por parte dos líderes empresariais. Especialmente porque a promoção da visão dos stakeholders e de temas como "responsabilidade social empresarial" e "investimento ético" produziram um debate sem precedentes sobre a ética e a vida empresarial. Contudo, quando se tenta desenvolver, no interior das empresas, uma ecologia moral sólida, não há substituto para $\mathrm{o}$ ato de continuar orientando-se por convenções de grande tradição, como o são a observância do Estado de Direito e a melhoria na compreensão da natureza da ética ${ }^{38}$. cos
${ }^{37}$ CHAFUÉN, Alejandro A. Justicia Distributiva en La Escolástica Tardía. Estudios Públicos, Vol. 18, (1985). p. 83.
38 GREGG, Samuel. Corporate Obligations Should Reflect Stakeholder's Best Interests. 2001. Disponível em: $<$ http://www.onlineopinion.com.au/view. asp? article $=1342>$. 